\title{
The Digital Currency Challenge for the Regulatory Regime
}

\author{
Retos del marco regulatorio para el dinero electrónico
}

\author{
GONZALO ARIAS ACUÑA \\ Universidad Adolfo Ibáñez, Chile \\ ANDRÉS SÁNCHEZ PULLAS \\ University of Melbourne, Australia
}

\begin{abstract}
Digital currencies pose several questions. First, finding the best definition. Digital currencies have specific features that make necessary to mention in its definition. The second puzzle that they present is the function of Internet. It is important because Internet is the vehicle for the good functioning of digital currency schemes. The network provides all the facilities to digital currency, but it also may be a place for criminal activity. The third question is the relation of digital currencies and the e-commerce. The electronic commerce is an antecedent of virtual currencies. The necessity to make the payment quicker and easier makes possible the growth of virtual currencies. Finally, there is the puzzle of the regulation. A complete regulation does not exist in the digital area. It is the nature of the Internet. It is a place where there are no financial rules. Criminal activity and improper use of Internet will increase over time.
\end{abstract}

KEYWORDS Digital currency bitcoin, electronic money, legal challenges, e-commerce. 
RESUMEN Existen diversas interrogantes en materia divisas digitales. En primer lugar, la búsqueda de la mejor definición. Las monedas digitales tienen características específicas que hacen necesario proponer una definición. El segundo rompecabezas es la función de Internet. Es importante porque Internet es el vehículo para el buen funcionamiento de los sistemas digitales de divisas. La red ofrece todas las facilidades para la moneda digital, pero también puede ser un lugar para la actividad criminal. El tercer enigma es la relación de las monedas digitales y el comercio electrónico. El comercio electrónico es un antecedente de las monedas virtuales. La necesidad de hacer el pago más rápido y más fácil hace posible el crecimiento de las monedas virtuales. Por último, está el rompecabezas de la regulación. Una regulación completa no existe en el área digital. Es la naturaleza de la Internet. Es un lugar donde no hay reglas financieras. Probablemente la actividad criminal y el uso indebido de Internet aumentarán con el tiempo.

PALABRAS Clave Divisas digitales, bitcoin, divisas electrónicas, desafíos legales, comercio electrónico.

\section{INTRODUCTION}

There are many ways to make money. One can earn money from its own job, from a business even you may have enough luck and win a lottery prize; others prefer to steal money. Yet, if you are a preternaturally talented computer coder, you can invent it. That is the case of Satoshi Nakamoto. He created and developed a new currency - Bitcoin - using only his computer configuration. (Davis, 20II: 2).

Digital currencies are possible because of Internet's development. In this essay, the main questions and issues related to the digital currency scheme will be analyzed. The paper will be divided into three parts.

First, this paper will expose problems for a definition of digital currency. Law journals and scholars commonly use a two-word combination of digital, cyber, electronic or e-, with money, cash or currency. The consideration of these concepts is the achievement of the concept of digital currency. (Tucker, 2009: 3 )

These terms, in popular use, may have very precise meaning. For this reason, it is a big problem to find a better definition of these concepts. 
Also, it is important the explanation of the role of the Internet and cryptography in digital currency schemes, in that sense, the first part will also deal with these aspects of the discussion.

Secondly, this paper will present the explanation of the technical approach of the digital currency system. For a better understanding, we will suggest as a study case the Bitcoin scheme. Bitcoin is nowadays the most developed digital currency available in the market. It is remarkable its use in both retail transactions and e-commerce.

Finally, we will discuss regulatory issues and the role of the State and local authorities in digital currency systems. There is a big challenge for the authority in finding the best regulatory regime for virtual currencies. Because they operate through the Internet there is no regulation and no legal structure for this issue. The nature of the web makes difficult to find of a regulatory regime for digital currency schemes.

Importantly, the critical question is whether people should adopt digital currencies for their ordinary transactions. We will suggest that this question is difficult to answer at the moment. Consumers are probably not ready for all the implications of digital currency schemes, maybe because of ignorance or lack of clear regulations. However, there is only one thing that we are sure of: Fiat currency and print money are impossible to supply for a digital representation of money.

\section{FINDING THE BEST DEFINITIONS}

The first issue to address is the terminology of electronic money and digital currencies. (Fullenkamp and Nsouli, 2004: 3) Users should understand these basic concepts. The proper differentiation of electronic money and digital currency is fundamental to understand the application of both instruments. Terms such as electronic money, virtual currency or digital currency involve different types of issues. Also, it is possible that the terms may not have a precise meaning in all the cases. In other words, this drives to an understandable confusion.

Importantly, the Financial Action Task Force (FATF) defines digital currency as «a digital representation of either virtual currency (non-fiat) or e-money (fiat) and thus is often used interchangeably with the term virtual currency» (Financial Action Task Force, 20I4: 26). Then this definition suggests two types of digital currency: virtual currency 
and e-money. In consequence it is necessary to address the differences between virtual currency, digital currency, and electronic money.

\section{DEFINITION OF ELECTRONIC MONEY}

Fiat money is any legally currency designated and issued by a central authority in every country (European Central Bank, 2012: 9). It is important to understand that electronic money is the digital representation of it. In other words, electronic money (e-money) is any electronic payment media. It is any material, device or system that conducts payment using electromagnetically sources (European Central Bank, 2012: 9).

The main difference is that e-money is a digital representation of fiat currency used to transfer electronically any value denominated in fiat currency. In other words, e-money is a digital transfer mechanism for fiat currency. The transfer is of the value that has legal tender status (Financial Action Task Force, 20I4: 26).

In the same way, e-money systems are generally either card-based or software-based. On the one hand, a card-based system uses a smart card for storage value (Loubser and Swart, I999: 355). Some examples of this system are credit or debit card. On the other hand, software-based system provides for storage value that does not involve any physical object (Loubser and Swart, I999: 355). For instance, electronic money «refers to an unified storage and transfer system that enables of value on a physical entity, such as a hard drive, within user's personal computer.» (Tucker, 2009: 594). The system described enables a secure transfer of fiat currency over the Internet (Tucker, 2009: 594).

\section{DEFINITION OF DIGITAL CURRENCY}

The definition of digital currency is still controversial. This is because the digital currency system is a new payment method never used before. Also, it is difficult to compare with the traditional money. Any authority or issuer can establish a definition, however digital currency schemes will have its definition according to its own features and purposes.

First, virtual currency is a digital representation of a value (Financial Action Task Force, 20I4: 4). The European Central Bank (ECB) considers a virtual currency as a type of unregulated digital money (European 
Central Bank, 20I2: 5). A central bank, credit institution or e-money institution cannot issue them. Instead, it is issued and controlled by its developers and members of a specific virtual community accepting it (European Central Bank, 20I2: 5). Second, virtual currency is a medium of exchange, a unit of account, and store of value (Financial Action Task Force, 20I4: 4). The main difference between virtual currency and electronic money is that the second one does not have legal tender status. On the other hand, electronic currency is a fiat currency with electronic representation (Financial Action Task Force, 20I4: 4).

This distinction carries out the necessity of a specific legal framework and other important consequences. First, in a virtual currency scheme is notable the absence of the traditional financial actors as central banks (European Central Bank, 20I2: 5). The oversight of the functioning of digital currencies is an issuers' responsibility. It implies that the typical financial sector regulation is not applicable. Second, there is no legal link between the digital currency and the fiat currency. Third, digital currency is denominated differently from fiat currency. This is because the complete control of virtual currencies is given to its issuer (European Central Bank, 20I 2: 6).

In the same way, virtual currency is associated with three main functions of money. First, it is a medium of exchange. It means that it is used as an intermediary in transactions (European Central Bank, 20I 2: IO). Second, it is a unit of account. Money acts as a standard numerical unit for the measurement of value and cost of goods and services (European Central Bank, 20I2: Io). Finally, it is also a store of value. Money can be saved and retrieved in the future (European Central Bank, 20I 2: IO).

In addition, digital currency is a privately issued electronic value that circulates through Internet (Mullan, 20I4: 4). It provides an instantly method to transfer funds and concluding agreements around the world. Furthermore, digital currency is a code or serial number that represent a value and uses the Internet as a vehicle. But, it is important to take into account that some digital currencies can work offline (Mullan, 20I4: 5).

\section{DEFINITION OF VIRTUAL CURRENCY}

In this part, we will highlight that both digital currencies and virtual currencies are synonymous. 
There is a discussion of the definition of the terms virtual currency and digital currency. In the opinion of the legal and economic experts, electronic currency and electronic money are synonymous with the digital currency (Tucker, 2009: 594). For instance,

[d]igital currency system... refers to the elements necessary to allow for the issuance, conversion and transfer of a given digital currency, including without limitation, the legal and operational entities that make up both the issuer of the currency and any all exchange agents who deal with it, the vaults in which the bullion is stored, the end-users who hold the currency, and the websites, servers and other necessary electronic infrastructure of both the issuer and the exchange agents (Tucker, 2009: 594).

We agree to this statement, however the global definition of digital currency involves a problem itself. The definition proposes that virtual currency is a type of digital currency. Then digital currency is the general term for all purposes, we will consider those terms as equivalent.

In conclusion, we can say that electronic money is a virtual representation of fiat currency. Furthermore, electronic money requires the equal amount of fiat currency. On the opposite, virtual or digital currency does not represent other currency.

\section{CRYPTOGRAPHY PROTOCOL AND THE ROLE OF THE INTERNET}

The cryptography protocol and the role of the Internet are fundamental in the digital currency scheme. First, digital currency system uses cryptography for the security of transactions. We will show how the digital currency system is similar to the digital signature system. This is because both systems operate through cryptography protocols. Second, Internet is the vehicle for digital currency schemes because it makes possible money's transaction easier and quicker.

\section{DIGITAL CURRENCY AS A CHAIN OF DIGITAL SIGNATURES}

In this part of the essay, it is necessary to connect the digital currency scheme with the digital signature procedure. It is necessary to explain both the security level and the performance of the digital currency system. 
In fact, the developer of Bitcoin, one of the most successful digital currencies, considers virtual currency as a chain of digital signatures (Nakamoto, 2009: 2). The author argues:

Each owner transfers the coin to the next by digital signing a hash of the previous transaction and the public key of the next owner and adding these to the end of the coin. A payee can verify the signatures to verify the chain of ownership. (Nakamoto, 2009: 2)

As mentioned, it is important to understand the concept of cryptography in the digital currency system (Mullan, 2014: 3). For example, the digital signature scheme uses cryptography as the main function of its operation. It guarantees the authenticity and integrity of a message in a high level of security. Cryptography is the method to codify a message. In the same way, only the real receptor of the message will be able to read it (Tyree, I997: I6). The same principle applies in the digital currency system. Only the real receptor of the money will be able to receive and save it on his account. For this reason, it is important to explain the digital signature as an example of the cryptography system.

Digital signature system offers cryptographic verification of the content of the document and the issuer. This system provides stronger security guarantees (Katz, 20I0: 3). For this reason, it is proper to consider this system as secure in a digital currency scheme. Digital signatures offer a cryptographic analog of handwritten signatures. They enable the transmission of data using the cryptography as a base of the security (Katz, 20I0: 4).

The cryptography system uses a public key cryptography. It consists in using separate keys in the encryption and decryption process (Tyree, I997: I7). The encryption of digital signatures requires that the sender and the recipient of the message have the same code (Davison, 2009: I08). The process to decrypt is the reverse of the process to encrypt. This process is the private encryption and allows to read the encrypted message (Davison, 2009: I08). Digital signatures use a key-generation algorithm. When a person uses the digital signature, then it generates a pair of keys, one is a public key, and the other is a private. The private key then allows the signer to certify a message (Katz, 2010: 3). Then, the receptor of the message obtains the private key from the issuer. Importantly, the issuer assures that the message originated has not been 
modified. Finally, the message can be verified by anyone who knows the private key. The receptor makes sure that the message comes from the issuer, and it was not modified (Katz, 20I0: 4).

In our opinion, this system provides an accurate security structure according to the type of security that digital currency needs in order to be feasible. In fact, the authentication of electronic data messages will become increasingly important for the commercial parties in the electronic commerce (Davison, 2009: II9).

\section{THE ROLE OF THE INTERNET IN THE DIGITAL CURRENCY SCHEME}

In this part, we will introduce the legal aspects and features of the Internet about the digital currency schemes. There are two main reasons for this inclusion.

First, some digital currency can work online or offline (European Central Bank, 20I 5: 8). Moreover, most of the time digital currencies request the use of Internet in transactions. In theory, digital currencies could serve as money for anyone with an Internet-enabled computer or device (Ali et al., 20I4: 4). That is the main importance of the role of Internet in the digital currency structure.

Second, in the authors of this paper opinion, digital currencies can take advantage of Internet characteristics. This is because Internet has important features that can be useful for the digital currency systems.

The main function of Internet is transporting digital information from one computer to another (Reed, 2004: 24). Any information can be translated for another device (Ali et al., 20I4: 4). Considering these statements, the vehicle for transferring digital currency is the Internet.

The Internet is the network of networks (Murray, 2010: 10). It is a system that connects many individual computer networks allowing the transfer of digital data. Internet is a telecommunications system for computer networks (Murray, 20IO: IO). It works through the TCP/IP protocol by breaking data in packets ready for the transmission and recombines them on the receiving. The system also handles addressing and routing the data and conducts to the proper destination (Murray, 2OIO: II).

In the same way, Internet was designed to prevent external control on the flow of information from a central operator (Mullan, 20I4: 66). 
It is important because the use of e-commerce has increased since its development. People and businesses may prefer a system that allows to avoid financial regulations and government supervision (Mullan, 20I4: 2). For instance, the developers of digital currency took advantage from the features of Internet. Also, for the first time in the history money and wealth could be stored, and payments could be instantly made without requiring any disclosure of personal information on the sender or the receiver. Importantly, e-commerce can only exist with a well-developed system of online payment (Mullan, 20I4: 3).

Therefore, the proper understanding of the principles of Internet will help the people to recognize the best use of digital currencies.

\section{Principles of the internet in relation to digital currency}

Digital currencies must follow the same principles of the Internet. This is because users match this currency with Internet characteristics. For this reason, it is important to analyze the features of Internet that can be used by digital currency in transactions.

First, users of digital currencies want to do safe transactions. The first principle of Internet is its net neutrality (Reed, 2004: I 8). Network neutrality is the principle that data packets on Internet should be moved impartially, without regard to content, destination or source (Murray, 20I0: 27).

Secondly, technology neutrality in the digital currency matters. Technology neutrality suggests that the "situations where information is generated, stored or transmitted are equal» (Mik, 2000: 5). In other words, the technology used for interchange data is not relevant (Mik, 2000: 5). The principle of technological neutrality considers that even when technologies change there is no need to change the rule because they were designed considering technology amendments.

Furthermore, a derivative application of the net neutrality principle is the non-discrimination principle. It requires that the broadband providers cannot discriminate against particular Internet content or application (Mik, 2000: 29).

Fourth, one of the most important demonstrations in this matter is the functional equivalent principle. It establishes that electronic documents will have the same level of acceptance and the same recognition 
as that if paper documents (Gabriel, 2006: 6). This principle primarily relates to writings and signatures. It means that writing and signatures have the same level of acceptance in any circumstance (Gabriel, 2006: 7).

In our opinion, these principles are key for the correct application of digital currency. This is because most of digital currencies, such as Bitcoin, work through Internet as the vehicle. Then the same Internet principles are applied to digital currency transactions. The net neutrality principle makes sure that transactions will be done just when the device used is connected to Internet. In the same way, the non-discrimination principle involves that transactions will not be discriminated by Internet providers, considering the amount or type of the business. The broadband providers will not discriminate between a retail and large transaction. Importantly, under these principles, digital currency can operate through any electronic device with Internet access. The issuers of digital currency do not to consider specific hardware for the transactions. It is because the currency will operate through Internet that is decentralized per se. In that sense, what needs to be highlighted is the use of Internet architecture as the primary structure for the correct operation of them. In consequence, the use of hardware is of secondary importance.

\section{BITCOIN AS A STUDY CASE}

In this part, the essay will continue with the exposition of Bitcoin as a case of analysis. Bitcoin is the best-developed system in digital currency matter (Velde, 20I3: I). Also, authorities around the world had recognized Bitcoin as the principal subject for regulation in relation to digital currency schemes. For this reason, we consider useful to take this example as a study case. In this part, the paper will analyse the technical and legal issues for Bitcoin. Finally, we will conclude by determining if this system is the best one to be adopted in the future.

\section{DEFINITION OF BITCOIN}

In recent years Bitcoin caught the attention of the regulators around the world. This was because its use is now the most popular in terms of virtual currency. It represents a large step forward regarding financial value 
(Kirby, 20I4: 190). Some scholars argue that Bitcoin has the potential to revolutionize global finance (Kirby, 2014: I90).

Bitcoin is a digital, decentralized, partially anonymous currency. It is not issued by any government or legal entity, and it is not redeemable for gold or another commodity (Grinberg, 201 2: I 59). Bitcoin has increased its scope in recent years. It is important to remark that Bitcoin is just a type of digital currency. It is the unofficial currency that circulates on the Internet (Velde, 20I3: 2). For the present paper, Bitcoin is the type of currency that completed all of the specifications of digital currency schemes previously explained.

In the same way, experts consider that Bitcoin is a revolutionary creation. For the first time in history, the requirement of an intermediary has been removed from the financial equation (Mullan, 2014: 89). Second, cryptographers consider Bitcoin as a system mirrored the features of cash. Furthermore, Bitcoin offers autonomy in transactions. Users can have one or more Bitcoin wallets they can set up a new wallet at no cost in anytime. This is a basic feature of digital currency accounts. Third, personal information of the user cannot be obtained. Finally, transactions are immediate between participants (Mullan, 2014: 90).

In fact, we can consider Bitcoin as a fiduciary currency (Velde, 20I3: 2). Fiduciary currency can be defined as «a currency without intrinsic value; it derives its worth from the trust users have in the issuer of the currency» (European Central Bank, 2015: 33). In other words, it has value because other people had given it. Bitcoin has value because it is accepted in the market. For instance, if buyers and sellers believe that the currency has no value then another person will not accept either (Velde, 20I3:3).

In conclusion, Bitcoin scheme is similar as using cash in commercial transactions. It is attractive for users. All of these statements had made Bitcoin an illustrative study case. The paper will now examine the technical performance and the advantages and disadvantages of using this digital currency.

\section{HOW DOES BITCOIN WORK?}

The functionality of Bitcoin is interesting to analyze for legal purposes. This is because Bitcoin is able to solve two challenges for digital money. 
First, the system controls its creation. Second, the Bitcoin scheme avoids its duplication (Velde, 20I3: 2). Both characteristics cannot be found in the traditional currency system because central banks have the monopoly for the creation of money and because it is clear that money can be duplicated. The two key aspects of Bitcoin scheme are the miner system and the proof-of-work system.

\section{Miner system}

As mentioned above, Bitcoin follows the principles of cryptography. It uses this system to validate the transactions and governs the production of the currency itself (Murphy, Murphy, and Seitzinger, 2015: I). The cryptography system has other uses, for example allows special users of the Bitcoin network to "gather together blocks of new transaction and compete to verify that transactions are valid - that the buyer has the amount of Bitcoin being spent and has transferred that amount to the seller's account» (Murphy, Murphy, and Seitzinger, 20I 5: 2).

In the same way, Bitcoin mining is the process where users provide computing power to verify Bitcoin transactions, secure the network, and keep everyone in the system synchronized together. Bitcoin mining provides appropriate tasks to process and confirm transactions. The new transactions are confirmed through a mathematical proof of work (KienMeng Ly, 20I4: 590). As a result, there is an entire industry dedicated to mining Bitcoins (Kien-Meng Ly, 20I4: 590). In other words, mining is a consensus system that confirms waiting for transactions. These transactions will be included in the balance sheet of each customer. The system is random and protects the neutrality of the network. ( «FAQ | Bitcoin. com» 20I5).

For these reasons the labor of miners is paramount. It allows that user does not care about the double-spend problem. In other words, the double-spend problem means that both the payer and payee are, usually, concerned about doing the payment and receiving it. In other words, the use if Bitcoins relies on the security of transactions. The customers are sure that their transactions were done and the receptors are also secure of the validity of the Bitcoin received. 
In complement to the miner system, there is the proof-of-work system. Together with miner system, they are the key to preventing falsification of the block chain (Velde, 20I3: 2).

In order to understand this system, we must think about the real money or fiat currency. When people exchange, for example, a gold coin, the coin's gold content, which it is costly to extract from the earth, proves that the people not counterfeit the coin. This will work only if it is reasonably easy for the receptor of the money to check the gold content. Bitcoin requires a similar proof of work from the miners (Velde, 2013: 2). It works «in the following way: A valid addition to the block chain must include the solution to a difficult mathematical problem, which is costly to find... the Bitcoin protocol provides an elegant solution to the problem» (Velde, 20I3: 2). Then the Bitcoin developed a transactions list.

The confirmation of the transaction is completed when the proof of work is verified. This proof is hard to generate because there is no way to create it, other than trying billions of calculations per second («Bitcoin for Individuals - Bitcoin», 20I5). This means, «[t]he currency can be exchanged because of all of the potential recipients have the means to verify the transactions and validate new ones»(Velde, 20I3:2).

Finally, these two systems increase security in transactions. Then the infallibility of Bitcoin is increasing. Retail and large users can have the certainty that the technical features of Bitcoin ensure the best option available in order to avoid the double-spend and the falsification.

\section{USES OF BITCOIN}

There are specific features that make the use of Bitcoin attractive for retail transactions. Bitcoin has many properties that could make an ideal currency for commercial transactions (Grinberg, 2012: 198). For this reason, it is important to take into account all of the specific characteristics that can increase the use of Bitcoin. 


\section{Bitcoin as a payment method}

Money is a medium of exchange (Proctor, 20I2: 22). People receive fiat money in exchange for a valuable well or service. For thousands of years, that medium of exchange has been adopted of a physical form. Money has an intrinsic value when it is a precious metal, or it can be a representation of this value (Velde, 2013: 3). It is clear the definition that some scholars give to this virtual currency. Bitcoin is a new kind of payment (Proctor, 20I 2: 22). For this reason, it is fundamental to consider that the most important function of Bitcoin as a payment method.

First, Bitcoin is a new manner to exchange money. This virtual money can work in the transactions from mobiles and personal computers (Nakamoto, 2009b: 3). Anyone can download the free software from a website or app store to send, receive and monitor Bitcoins transactions (Financial Action Task Force, 2014: 6). It operates through a Bitcoin address or a wallet. The digital wallet is a computer file that allows storing Bitcoins over the Internet (Kirby, 20I4: 205). The virtual currency wallet is the software or another mechanism for holding Bitcoins and make personal transactions. The digital wallet facilitates the participation in the virtual currency system easily. It also provides to users the balance of transactions. Importantly, another issuer different than the Bitcoin can provide the wallet system (Financial Action Task Force, 20I4: 6).

Second, Bitcoin allows fast international payments. Sending a Bitcoin across the border is easy. It is because there is no banks or third person involved in the process. Bitcoin works through the Internet. Also, because of it, there is no especial limitation or maximum amount that people can send or receive per transaction (Nakamoto, 2009b: 3 ).

Bitcoin is highly liquid, and it can be used to send payments across the Internet. Importantly, Bitcoin overcomes the barriers to international trade. It allows the cross-border payments and increases the possibility to trade with the increasing virtual communities (European Central Bank, 2015:4).

In the same way, the payment with Bitcoin is irreversible. Any transaction issued with Bitcoin cannot be reversed (Nakamoto, 2009b: 5). It is an important security for the person who receives the payment. The seller of a good or provider of a service can trust that the payment cannot be reversed. It can increase the trust in the commerce. On the other 
hand, the Bitcoin system can detect the payment made to an invalid address by a mistake. The system will not let to send the money to this invalid address. It is an important protection to the consumer. Furthermore, once a user sends a Bitcoin to another user, the recipient can only refund the transaction (Kirby, 20I4: 193). This function is similar to the fiat currency or real money.

\section{Bitcoin and Electronic Commerce}

In this point, it is important to consider the use of Bitcoin in the e-commerce. Electronic commerce is the commerce that uses a digital form or an electronic platform. It means buying and selling goods and services on the Internet (Wang, 20IO: I7). The term electronic commerce encompasses transactions of information, data, products and services using online communications facilities.

Electronic commerce is conducted in a digital form on an electronic platform (Wang, 2010: I8). In these days, the e-commerce is constantly growing. The continuing flow of information and the increasing use of Internet make international commercial transactions quicker and easier. The geographic distance is not a problem. Every person has direct access to the products information via company's website (Wang, 20Iо: I8). Taking into account all of these statements, this new form of payment is revealed as necessary.

The electronic commerce is important in the current economy. Electronic communications and transaction processes allow dynamic competition in the market. It is because the sellers develop a new information-based online product. In other words, the invention of electronic commerce has been beneficial to the global economy. Instead of traveling long distances to visit a shop or factory, customers can buy and sell goods by an electronic device with Internet connection. Also, buyers can surf websites and compare products according to the specifications. After that, buyers pay and the product is delivered to the place chosen for this effect (Wang, 2010: I9). 
In this part, the essay will examine the advantages for customers of using Bitcoin. As mentioned above, Bitcoin is one of the most successful digital currencies in the market. The advantages of its use are related to the benefits of using digital currency in general. For this reason, we will present the advantages of Bitcoin as the general advantage of digital currency (European Central Bank, 20I2: I 8).

The first digital currency to gain widespread adoption is Bitcoin. In fact, Bitcoin has the highest market value at about \$I rbn. (Wild, 2016: 2). Bitcoin has demonstrated that the algorithms driving it are robust. In addition, Bitcoin runs on an open-source protocol that operates across a network of user's computers. According to the Financial Times Bitcoin flaws are preventing it from being more widely adopted so it can become a means of payment as big as MasterCard or Visa. This is the key of the success of Bitcoin as digital currency over other digital currencies. (Wild, 20I6: 2)

There are several reasons for a virtual community to use a digital currency. In simple words, the uses of digital currencies «can help motivate users by simplifying transactions and preventing from having to make the personal payment in purchases»(European Central Bank, 20I2: I8). There are many reasons to choose Bitcoin as a payment method rather than other online payment methods such as credit or debit card. For this paper, we will consider three of the main advantages of Bitcoin scheme.

\section{Lower Fees in the Transactions}

In some cases transactions with Bitcoins are fee-free. Sometimes a transaction fee is required. Usually it worth less than 40 cents of US dollars («Bitcoin Fees | Bitcoin Transaction Fees Explained», 20I 5). This low fee is to incentive the miners to continuing with their work ( «Bitcoin Fees | Bitcoin Transaction Fees Explained», 201 5 ).

The cost related to the usage of digital currencies is considered low. It is important to note that when Bitcoin users need to convert it to the fiat currency, there is no foreign exchange cost. Therefore, we can acknowledge the cost-efficiency to use the system, particularly in cross-border transactions. In the same way, a private digital currency that flows on- 
line has the benefit of lower transactions cost and fees. Bitcoin micropayments are also widely used it is because the expenses for using this network are lower than a credit card in a small transaction (Mullan, 20I4: 5-6).

The question that arises is why transactions fees are currently low (Ali et al., 20I4: I). In fact, the marginal cost of verifying transactions by miners is higher than the verification done by the centralized payment system. Moreover,

while the marginal cost for traditional payment system may be expected to remain broadly constant over time, those incurred by digital currency miners may be expected to rise as their usage increases and in addition to that - to increase over the time because of an incentive for overinvestment in new equipment (Ali et al., 20I4: 6).

There is an elegant solution for the high cost of mining. Low transaction fees for digital currency payments are largely driven by a subsidy. The miners receive this subsidy. The size of the subsidy depends on the current price of the digital currency and the beliefs of the miners about the future price of the digital currency. For instance, there is a competition in the mining services. Miners compete for each other to catch more acceptances (Ali et al., 20I4: 6). In other words, the user can acquire new Bitcoins by serving as a miner. The cost of the authentication of the transactions is assumed by the system, not by the users. For this reason, fees over each transaction are lower than the other payment system (Murphy, Murphy, and Seitzinger, 20I 5: 5).

Second, the transaction's fees go to the miners. It is important to bear in mind that the miner's work is a business. The manufacturer produces specialized mining hardware, therefore users must redeem the miner's labor. Instead of the transaction fee, it continues lower than other online payment fees. In fact, Bitcoin Company is working to reduce the fees until it becomes $\circ \%$. Third, one of the strongest advantages for the payee is the low cost of acceptance. The payee just needs to open an account in one of the virtual currency systems (European Central Bank, 20I 5: 4). In the case of Bitcoin, it is the Bitcoin wallet. The Bitcoin system does not operate through a financial institution. This third party in the transaction may ask for a fee in the operations (European Central Bank, 20 I 5: II). Another advantage is that «the payee might also benefit from the 
reduced payment transaction verification and settlement time, which is especially valuable for those online sales with shipping after receipt of the payment» (European Central Bank, 2015: I9).

\section{The Absence of Intermediary}

Since the formation of the Federal Reserve System one hundred years ago the typical banking system has led the monopoly over the methods of payment (Mullan, 20I4: I 47). In all countries, the national authority supervises and enacts regulation for the payment methods. With the introduction of digital currency, the role of the national authority over financial payments came to an abrupt end (Mullan, 20I4: I47). As mentioned, issuers only control the technical framework and a third party does not verify the transactions.

It is relevant to mention that Bitcoin is one step ahead from the conventional digital currency systems (Tucker, 2009: 593). A typical digital currency scheme bases its operation in one single issuer and multiple exchange agents. Earlier online digital currency failed in the intention to avoid the third party in the transactions. The issuer buys physical value, and he stores the value in digital currency units (Tucker, 2009: 593). There are some issues that we can mention in the absence of the third party.

First, one of the most promising feature of Bitcoin is the financial freedom of the parties to a transaction. The payments and capital flow are perfected anywhere in the world at any time without restriction. Any authority or financial institution will restrict the number, the amount or the reason for the transaction. The freedom of Bitcoin produces and promotes the use in retail and large transactions (Mullan, 20I4: I47).

Second, the "peer-to-peer transfer process is absent of any middleman and third-party risk» (Mullan, 20I4: 67). In the absence of an intermediary, the risk of failure of this third person does not exist. Also, «[i]n many jurisdictions around the world, significant inflation and restrictions on capital flows are forcing citizens to seek financial freedom through alternative currencies such Bitcoin» (Mullan, 20I4: I I4). People need assistance to circumvent soaring inflation, capital controls, and bank counterparty risk. Users prefer Bitcoin over than traditional payment system because there are no restrictions on capital flows. In 
the same way, Bitcoin can move across international borders (Mullan, 2OI4: II4).

Third, this independence from authority allows nodes on the network to increase the currency supply at a current average rate of about 25 new Bitcoins every ten minutes (Mullan, 20I4: 89). On the other hand, in a pure bank system, the national authority exercises some level of control of the total amount of money in circulation. This control is more difficult when the national authority does not issue the money. In the same way, the issuer cannot discriminate the user considering a number of their debts. It is possible because of the absence of central authority.

In our opinion, Bitcoin takes advantage of the neutrality of the Internet. The network moves across the world without restriction. In the network, everybody is on the same platform. The Internet does not recognize boundaries between countries. Also, there are non-technical impediments against the liberty of the circulation of Bitcoins. It makes that people can interchange digital currency freely. This liberty is fundamental in the business world because commercial agreements need be as fast as is possible.

\section{Anonymity}

Another advantage of digital currency is the anonymity in transactions. Bitcoin is a system that lacks a direct connection to an owner. For this reason, the system could be called anonymous or pseudonymous. Financial analysis of this transaction could be extracted only from the IP address of the user's computer (Mullan, 20I4: 90).

Some scholars consider Bitcoin as a pseudonymous currency rather than anonymous. It is pseudonymous because if a person's identity were linked to a public key, one could look through the record of the transactions in the block chain and easily see all transactions associated with that key (Kirby, 20I4: I96). Although Bitcoin is not a completely anonymous, the users of it have a higher level of protection and privacy than in the traditional digital transfer services (Kirby, 20I4: I96). This characteristic carries some advantages.

Frist, the anonymity feature can be a relevant factor for users that want to protect their privacy and their sensitive information. In this way, digital currency system is a card-not present-payment. People do not transmit personal data and sensitive payment data. Also important, the 
payment cannot be linked to a payment instrument or payment account or person. Instead of these securities, miners verify all of the transactions to avoid the fraudulent payment or double-spend problem. That is the problem with other online payments methods. For example, payment with credit card requires a complete record transaction of the purchase (Tyree, 1997: 87).

Second, people can hide transactions for different purposes. It is because users can send Bitcoin from one computer to another. Importantly, Bitcoin system allows users have non-registered accounts and the possibility to generate multiple Bitcoin addresses (European Central Bank, 20I2: 2I). In other words, those who seek a heightened degree of privacy may find more comfort using Bitcoins for their (legal) commercial and financial transactions. The risk of identity theft may also be lower, and some may find the removal of government from a monetary system attractive.

Third, Bitcoin developers argue that it is "probably the most transparent payment network in the world» («Bitcoin for Individuals - Bitcoin», 2015). The issuers of Bitcoin recommend users to take all of the good practices to protect their privacy. First, they recommend using new addresses to receive new payments. Also, users can have multiple wallets for different purposes. It is fundamental because it is not possible to associate all of the wallets to one person («Bitcoin for Individuals Bitcoin», 2015). Second, it is recommendable to be careful with public spaces. The recommendation is about publishing a Bitcoin address on public space such as a website or a social network («Bitcoin for Individuals - Bitcoin», 20I5).

Finally, experts argue that transferring Bitcoins is much like transferring cash. Bitcoin cannot be more anonymous than cash («Bitcoin for Individuals - Bitcoin» 20I5). The only difference is that Bitcoin uses Internet. In our opinion, people prefer a payment method similar to cash for certain transactions. Importantly, there is a full transaction record. It makes sure the users that payment was done successfully.

\section{DISADVANTAGES OF USING BITCOIN SYSTEM}

In the present part of the essay, we will discuss some disadvantages of Bitcoin system. We can appreciate this barrier in different points of view. 
First, disadvantages from the user's view. Second, there are barriers under the legal authority approach.

\section{Legal Tender Status}

First, Bitcoin has not a legal tender status in any country. Any government or jurisdiction issues or guarantees digital currencies (Financial Action Task Force, 20I4: 4). In the same way, Bitcoin does not have all of the attributes of government-issued currency. As a result, Bitcoin is a voluntary currency, and no one can force another person to accept it as a payment method (Mullan, 20I4: I2I). It is a problem related to the non-legal tender status of Bitcoin. In fact, no creditor is obliged to accept payment with it to discharge a debtor of its debt (European Central Bank, 20I 5: 24).

It means that people can use virtual currencies as contractual money. It is necessary that the terms and condition of the purchase the seller accept Bitcoin as a payment method (European Central Bank, 20 I 5: 25).

Second, it is a problem of the level of acceptance of Bitcoin and digital currency in general (European Central Bank, 201 5: 25). Indeed, issuers of Bitcoin accept that the degree of acceptance is a disadvantage of the system. They argue that many people are still unaware of Bitcoin. Every day, more business accepts bitcoins because they want the advantages of doing so, but the list remains small and still needs to grow in order to benefit from network effects («Bitcoin for Individuals - Bitcoin», 20I 5 ).

Third, there is another effect from the non-legal tender status related to the authority's perspective. Bitcoin users are not subject to registration, reporting and recordkeeping regulation (Kirby, 20I4: 20I). In fact, Bitcoin is a decentralized currency (Velde, 20I3: I). It means that operates without government oversight. In our opinion, this is a big issue. The authority cannot verify the amount of digital currency flowing in the market. In the same way, this system needs a different regulation for markets participants instead of the regulation over the currency itself. The government needs to create a safe regulatory environment for the transactions (Kirby, 20I4: 206). 


\section{Volatile Price}

There are some issues related to the volatility of the price and the intrinsic value of digital currencies. We can remark some consequences that will determinate its position in the market.

First, there is an interesting statement about the value of Bitcoin proposed by the developers. They insist that Bitcoins have the characteristics of money or fiat currencies («Bitcoin for Individuals - Bitcoin», 20I 5). The difference is in the intrinsic value. Bitcoin is based on the properties of mathematics rather than relying on physical properties or trust in the national authority («Bitcoin for Individuals - Bitcoin», 2015). As a result, the value of Bitcoin is determined by the level of trust and adoption of users («Bitcoin for Individuals - Bitcoin», 2015). In the same way, the price of Bitcoin depends on the supply and demand. Speculation can dominate the market of Bitcoins to increase their price (Murphy, Murphy, and Seitzinger, 20I 5: 7). It is one of the main circumstances that trigger the volatility of the price.

Second, the characteristics per se of digital currencies increase the floatation of their price. In fact, scholars argue that the price of Bitcoin has been volatile since its creation. The rate of Bitcoin exchange to US dollar is subject to appreciations and depreciations in value (Murphy, Murphy, and Seitzinger, 201 5: 7). In fact,

During March $20 \mathrm{I}_{3}$ and April 2013, Bitcoin's dollar exchange rate rose from about $\$ 50$ to $\$ 350$ and then fell back to near $\$ 70$. Bitcoin's price moved up even more sharply during the fall of 20I3, rising from near $\$ 50$ in September to more than $\$$ I, Ioo by early December... By mid-January 2015, a Bitcoin was priced near \$200 (Murphy, Murphy, and Seitzinger, 201 5: 7).

As discussed earlier, the volatility of the price suggests that speculative investors manage the market of Bitcoin. Also, it remarks that the price of Bitcoins is treated as a commodity more than a medium of exchange (Murphy, Murphy, and Seitzinger, 20 I 5: 8).

Third, the high volatility of digital currencies increases the risk in the bi-directional flow. Business with digital currencies can be affected by this situation. For example, the seller of a good using virtual currency can receive it in one exchange rate and after sell it or buy other good at 
another rate (European Central Bank, 201 5: 23). For this reason, people can use digital currency as an investment through a speculation vehicle (European Central Bank, 2015: 23). Critics of digital currencies have argued that all of the currencies should have an intrinsic value (Negurita, 20I4: 246). For example, the exchange value of gold in other assets is essential to explain the price of the currency. Without this parameter, it will be complicated to increase the use of Bitcoin as a medium of exchange (Negurita, 20I4: 246).

Fourth, no authority regulates the price of Bitcoin. The activity to interchange with Bitcoins is not overseen by any technical agency (Mullan, 20I4: 28). In the same way, it is a trouble the institutionalization of this coin without an official issuer. Actually, money and legal tender status are given and defined by law. Also, «[c] ash must be printed and, if it would print cash as scriptural money is created electronically by banks, it would quickly generate a hyperinflation» (Negurita, 20I4: 246).

In our opinion, digital currencies can circulate neither without restriction nor in a regulatory regime nor a control over the price. For instance, the fraudulent production of Bitcoins can increase. Also important, virtual currency schemes can become inflationary currencies because it has lower production cost and physic existence.

\section{THE RISK OF USING BITCOIN}

Recently, the European Central Bank showed concern over digital currency under the authority's approach. In its opinion, the role of the central banks could be affected by the high use of digital currencies. The principal areas affected could be the financial stability, monetary policy, and price stability (European Central Bank, 20I 2: 33 ).

First, virtual currency schemes could affect price stability «if they affect the demand for the central bank's liabilities and interfere with the control of the supply of the money through open market operations». (European Central Bank, 20I2: 33-34). In the same way, the European Central Bank argues that in extreme circumstances virtual currencies can supply the uses of the fiat currency. It is necessary to say that there is a short number of units of value of virtual currencies. For this reason, this is not a real risk for the price stability, but it is important to consider this matter by the future regulation (European Central Bank, 20I 2, 37). 
Second, digital currencies can affect financial stability. The safeguarding of financial stability requires the identification of the main sources of the risk vulnerability. In the case of digital currencies, it is difficult because it works outside the bank system (European Central Bank, 20I2: 37). In the same way, the stability also takes into account the prices in the market. For this reason, the volatile price of the digital currencies can increase the speculation over the market (Ali et al., 20I4: 8).

It is important to clarify that today the total value of all digital currencies is too small to affect the whole system. Also, the digital currencies have a limited connection to the real economy. But this matter cannot be ruled out because the situation could change substantially in the future.

Third, it is the monetary stability. The possible scenario could be the higher use of digital currencies than fiat currency as a payment method. The European Central Bank argued that digital currencies schemes work better for retail payments because of their characteristics. In other words, participation in these schemes exposes their users to credit, liquidity, operational and legal risk within the virtual communities; no systemic risk outside these communities can be expected to materialize in the current situation (European Central Bank, 20I 2: 38 ).

In our opinion, these potential risks can be dangerous if the digital currency schemes increase the number of its users. Currently, the low level of acceptance marks the point of the balance in order to avoid risk. Authorities should not allow that the risk is taken and absorbed by the users over the issuers.

\section{PROPER REGULATION FOR DIGITAL CURRENCIES}

The Bank for International Settlements (BIS) had established some regulatory issues for digital currencies based on distributed ledgers, these issues cover three main fields. First, it is the consumer protection issue. Second, the issue covers the prudential an organizational rules for the different stakeholders. Finally, the BIS also consider the specific operating rules as payment mechanism. (Bank for International Settlements, 20I 5: I 2).

In addition, the BIS considers the nature of digital currencies, which is typically online, therefore it is not limited to national jurisdictions. For these reason the BIS proposed a guideline for a proper regulation of digital currencies. 
The main options are identified in this way. First, BIS proposed a system of public warnings, disclose of information for investors and buyers of the currencies. In addition, BIS recommend the elaboration of research papers given by the authorities using official information. Second, BIS recommends regulation of digital currency administrators. For example, the administrators must keep records and report the authorities the transactions. In addition, it is proposed regulation for digital currency exchangers in the same way. Also, BIS proposes consumer protection measures mostly like payment guarantee and redeemability. Third, BIS suggests the application of regulation based on the interpretation of «how existing framework may be applied to digital currencies intermediaries» (BIS, 20I5: I3). In the same way, BIS encourages the authorities to dictate regulation covering all three areas (consumer protection, prudential rules for stakeholders and specific rules as payment system). (BIS, 20I 5: I3)

Bitcoin and digital currencies are decentralized currencies. It means they are not under control of the power of the State. This scope suggests another negative effect because Bitcoin is also outside to the protection of the state (Velde, 20I3: 2). In fact, Bitcoin offers none of the traditional the protection afforded by government to traditional currencies, such as the ability to pursue fraud or to print new money to keep the system afloat.

It could be one of the principal disadvantages of using Bitcoin. For this reason, it is important to propose some possible solutions.

First, it is necessary public and private cooperation. National authorities and Bitcoin exchangers should work together to protect the integrity in the Bitcoin marketplace. Regulators should know how Bitcoin works and its technical framework before taking action. The regulation should incorporate the necessities of the system and the participants in the transactions (Kirby, 20I4: 206).

Secondly, effective enforcement for non-complaint Bitcoin exchanges. It can increase the credibility and the level of trust of the participants in the transactions (Kirby, 20I4: 2II).

Third, experts propose a hybrid system of regulation based on the suspicious activity and a report model. These mechanisms suggest cooperation and disclose of information. Bitcoin as a business should share information with the authority to avoid inappropriate behavior to the 
participants. In other words, Bitcoin should report suspicious conducts to the participants when a money laundry or other criminal relation exists. Also important is the information shared for tax purposes (Kirby, 20I4: 200).

In our opinion, national governments should build regulatory frameworks that motivate trust in Bitcoin. Considering that the use of new technologies is growing, it is important to find the best regulation instead of prohibit the use of digital currencies. The governments and customers, in general, should to consider that fraudulent behavior exists in all currencies (Kirby, 20I4: 2I4).

\section{REGULATORY ISSUES FOR DIGITAL CURRENCIES}

In this part we will present regulatory issues and challenges that authorities around the world have to face to address and regulate digital currencies schemes. There are some important considerations: first, the legal status of digital currency systems and the recognition of them as money in a different jurisdictions; second, there is the regulation problem itself. For instance, there are some core questions that may arise. How can the authority regulate something that is partial outside of the boundaries of the country? Who will regulate a decentralized system? Which is the jurisdiction of a digital currency system?

\section{THE ROLE OF THE STATE IN DIGITAL CURRENCY SYSTEM}

In this part of the article, we will evaluate the role between the State and Bitcoin. Over the history, the State had been involved itself in the issuing of money. Importantly, authorities in every country are in charge of the issuing and regulation of currencies according to the monetary politics and regulatory regimes.

There are two principal roles of the State about the money. First, states establish their monetary system. It allows the national authority to create physical money. Second the role of the State in authorizing the issuing of notes and coins. Under this approach, the

money must be issued under the central authority of the State concerned... only chattels issued by the legal authority of the State could acquire the character of 'money', and that the value to be attributes 
thereto is fixed by law, rather than by reference to the value of the materials employed in the process of production (Proctor, 20I 2: 3I7).

In the same way, these statements are related to the sovereign of the State and the monopoly over the currency. The state has the power to enact exchange controls and other regulation. Under this approach, only the currency created by supreme legislative authority can be considered as money (Proctor, 20I2: 3 I 4).

Also, scholars argue that central banks will have to rebuild the monetary policy to adapt to the new necessities of digital currency. On the other hand, others experts argue that monetary policy will lose its relevance to economic activity if the use of digital currencies increases (Fullenkamp and Nsouli, 2004: 4).

In addition, we consider that the best solution is the incorporation of the digital currencies scheme in the monetary policy. For this purpose, this policy will consider the three functions of money in order to treat digital currency as fiat currency. It means that the digital currency system itself should be able to serve as store of value, medium of exchange and unit of account (Fullenkamp and Nsouli, 2004: 5). Importantly, digital currencies schemes must keep the possibility to redeem the currency in the fiat currency every time (Fullenkamp and Nsouli, 2004: 5).

\section{Current Regulatory Regimes for Digital Currency in Different Jurisdictions}

The Library of Congress of United States of America made a report of the regulatory regime or statements from central banks or government offices around the world on the handling of Bitcoins and digital currencies (Library of Congress of United States of America, 20I4: I). In this report, it is notable the case of China and Brazil that have specific regulations applicable to Bitcoin use. These regulations showed widespread concern about the Bitcoin and the possible impact of national currencies. (Library of Congress of United States of America, 20I4: I) There are other jurisdictions that have different consideration of digital currencies. The authors of this essay have followed the alphabetic structure of the Library of Congress of the United States of America's report to explain the evidence of the study. 
Australia. The Australian Taxation Office issued a paper in 2014 in relation to the taxation treatment of Bitcoin and other virtual currencies. Under the taxation office's point of view, Bitcoin is neither money nor foreign currency. The agency considers that Bitcoin is not a financial supply for goods and services tax. On the other hand, Bitcoin is considered as capital for capital gains tax (Australian Tax Office, 20I4).

Brazil. The Brazilian case is particular because the legislative authority enacted regulation that creates the possibility of the normalization of mobile payment system and virtual currency system. For this purposes, the regulation recognizes all of the resources stored on a device or electronic system as the payments method. The virtual currencies systems allow the end user to perform a payment transaction (Library of Congress of United States of America, 2014: 3 ) .

Canada. Canada does not have a specific law or regulation for digital currencies schemes. In Canada Bitcoin or another digital currency is not considered as legal tender. In the same way, the Canadian bank argues that only the notes and coins issued by the Canadian Bank have legal tender status in this jurisdiction (Library of Congress of United States of America, 20I 4: 4)

Chile. According to news reports, there is no space for the use of Bitcoin as a transactional mechanism therefore buying virtual currencies still remains a cumbersome. However, there is a young community of information technology professionals who are promoting its use. Furthermore they have opened the first virtual money exchange store in Chile. Nevertheless, because there is no regulation on the use of Bitcoins, transactions are informal in nature and mainly conducted among friends. (Library of Congress of United States of America, 20I4: 5)

Finally in 2013, a group founded a self-sustaining organic farming community called Galt's Gulch Chile in central Chile with an economy based on Bitcoins. (Library of Congress of United States of America, 20I4: 4) The efficiency is yet to be studied.

United Kingdom. The national authority in the United Kingdom recognized that the Bitcoin system is unregulated. In fact while Bitcoins are not regulated, it has been reported that Her Majesty's Revenue and Customs has classed Bitcoins as single purpose vouchers, rendering any sales of them liable to a value-added... this has been strongly criticized by those selling Bitcoins. 
All of these examples of regulatory regimes demonstrated that there are different opinions about digital currency schemes. For this reason, it is difficult to provide a definitive regulatory framework on this topic. In this line of thought, the absence of a commonly understood definition of Bitcoin has lead to a widespread concern about the system's possible impact on national currencies. Furthermore, the concern is also revealed by the absence's potential for both national and global criminal misuse, and the implications of its use for taxation, fraud, etc. Finally, the findings of the report reveal that the debate over how to deal with this new virtual currency still remains contested.

\section{The Regulation for Digital Currency Schemes}

The regulation of digital currency systems is a big challenge for the authorities. Considering that digital currency use the Internet as a vehicle we will suggest that the same principles for the regulation of the Internet should to be applied to digital currency schemes.

The authority. The regulation of the network is not an easy task. Legal provisions are limited. There is no social or political control over the network. The use of the web and the transactions online has no oversight. Only one organization is in charge of preserving the operational stability of the Internet. That is the Corporation for Assigned Names and Numbers (ICANN). ICANN is a non-profit private sector corporation formed by a broad coalition of the Internet's business and technical communities. It also has the responsibility for the four key Internet functions: «the management of the domain name system, the allocation of the IP address space, the assignment of protocol parameters, and the management of the root server system» («Resources - ICANN», 20I 5 ).

The ICANN does not provide the function of the authority in the digital currency scheme. On the other hand, it is the only corporation that oversights the correct function of the system. In conclusion, at the moment, there is no authority that can control the digital currency system. Furthermore, it is clear that a global framework for a regulation is a very difficult project.

The territorial problem. In terms of territorial application of laws, it is widely understood that the law applies inside the state's territory. The ability to enforce the law ends with the boundary of each country. This 
reflects a huge problem for the regulation of Internet because the cyberspace does not recognize the boundaries of the countries. Web users are no subjects to a particular state's laws (Reed, 20I 2: 7). The digital currency scheme has the same problem. In the same way, the national authority needs a geographical presence in order to enable lawmakers to use the enforcement powers against who do not comply the law (Reed, 201 2: 7).

Another problem is that digital currencies have no physical existence. It is difficult to enforce by law something that has no tangible existence (Reed, 2012: 6).

The alternative solution to this present problem is that Internet would develop its own governing institution. This institution can legitimate the use of the web and determine which laws would apply (Reed, 20I 2: 25). This idea is appropriate for the general framework of the regulation. Then, every country should agree to the creation of a central authority for digital currency systems. In theory this framework is possible, however in practice it may impossible to achieve.

Jurisdictional problem. The rules that determine competence are jurisdictional rules that establishes what laws should be obeyed (Kohl, 2007: I 5). The problem arises when we have to look the rule that we must follow in the transactions or dispute resolutions. First, it will depend on the nature of the dispute. For example, if the dispute or matter is private, the private international law will apply. On the other hand, if the matter is about the criminal activity, the local prosecution will act (Kohl, 2007: 27).

In the same way, it is important the harmonization of the law. National authorities should have a consensus with the authorities of other countries in order to provide a proper regulatory regime. This consensus should include rules of the jurisdictional problems. This matter is still ambiguous. For this reason, we suggest that the jurisdiction of the transaction with digital currency should apply the general principles. In other words, the private and commercial disputes should not establish difference if the payment was made with digital currency or fiat currency.

\section{OTHER LEGAL ISSUES}

Governments are increasing the legislative activity about Bitcoin and digital currencies. In the United States, Federal regulations are growing. 
The regulation focuses on encouraging the agencies to confront criminal hacking of Bitcoin wallets and kidnappers requiring ransom payment in Bitcoin. These examples show the advances in the legislation about criminal behaviours. It is important to mention that the most important issues in relation to the digital currencies schemes are the anti-laundering and tax regulation.

\section{Criminal Regulation and Digital Currencies}

Julian Assange was probably unsurprised when he noted that the PayPal stopped processing a donation to his organization. The reason could be the political pressure over the company. (Grinberg, 20I2: I62) In this case, a pseudonymous crypto currency could help to continue receiving the donations. This showed a possible use of Bitcoin for criminal purposes.

Criminals can use digital currencies as a mean of interchange between illegal drugs, weapons and information. Criminal activity does not limit its operation to Bitcoin. In 2006, the US authority found an online currency called Liberty Reserve. After a judicial procedure, the co-founder of Liberty Reserve pleaded guilty to money laundering (Hett, 2009: 3). As mentioned above, criminals use digital currency as a vehicle for money laundering or terrorist financing. The scheme is a perfect way to transfer money faster and anonymous. The regulation of digital currencies is a big challenge for the authorities because the nature of them is different from other institutions. The financial organizations are subject to strict control and regulation. For example, financial institutions have the obligation to maintain customer identifications records, filling suspicious activities reports, reporting the transfer of a large amount of money, and identify the customers (Hett, 2009: 3).

In some jurisdictions there is some regulations against these criminal activities. For example, in the United States, there are criminal anti-laundering laws. These rules allow proceedings against criminals when they use a financial institution for their purposes (Murphy, Murphy, and Seitzinger, 20I 5: 66). It is possible because the law establishes the recordkeeping and the reports of cash transactions exceeding amounts set by the authority (Murphy, Murphy, and Seitzinger, 201 5: 66). The big problem is when the transaction is made in unregulated currency. 
Definitely, national authorities are concerned about the possibility of criminal use of digital currencies. Also, virtual currencies schemes are difficult to regulate because these schemes provide a flexible and potentially undetectable method for funds transfer (Hett, 2009: 9).

For this reason «On March I8, 20I3, Treasury’s Financial Crimes Enforcement Network (FINCEN) issued interpretative guidance requiring Bitcoin exchanges-individuals and business that change Bitcoins into U.S. or foreign currency-to register as MSBs pursuant to the BSA». (Murphy, Murphy, and Seitzinger, 20I 5: 2I)

In the same way, it is important the contribution of the Financial Action Task Force (FATF). This agency established a guidance for a riskbased approach to virtual currencies ( Guidance for a Risk-Based Approach to Virtual Currencies», 201 5: 3). The purpose of this guidance is a help to the national authorities to develop regulatory responses against criminal uses for digital currencies systems. Importantly, this guidance also intent to help the private sector to understand the relevant facts and the risks of the schemes ( Guidance for a Risk-Based Approach to Virtual Currencies», 201 5: 3).

FATF proposed some possible regulations in this matter. First, it claims to the application of the risk-based approach to the elaboration of anti-money laundry and financial terrorist regulation. In this way, «countries should strengthen the requirements for higher risk situation» ( "Guidance for a Risk-Based Approach to Virtual Currencies», 20I 5: 8). This requires that the national authority should be able to identify, understand and assess the risk and take action to mitigate risks. Second, the guidance recommends national cooperation and coordination on the criminal uses of digital currencies. In other words, FATF considers that the national coordination makes possible the mitigation of risk in the scheme. Third, it is important the risk-based regulation of the new technologies. Governments should adopt regulatory regimes for new business practices and the new payment mechanisms. Finally, there are some recommendations related to registration ( «Guidance for a Risk-Based Approach to Virtual Currencies» 20I 5: 8). Also, because convertible VC exchangers that transfer value digitally, via the internet, are not subject to territorial boundaries and generally offers by VCPPS to persons in countries in which they are not physically present, it is very important that all home countries apply domestic licensing or registration requirements. 
In our opinion, it is a challenge for the authorities to enact regulatory regimes to virtual currency schemes because of its nature. The regulation needs to be established in general.

\section{CONCLUSION}

Digital currencies and distributed ledgers are an innovation. The use of digital currencies could have an important impact on many areas, especially on payment system and services. The investigation has demonstrated that these impacts imply the disruption of existing business models and systems. In the same way, the use of digital currencies needs the emergence of new financial, economic and social interactions and linkages.

Unlike traditional e-money, digital currencies are not a liability of an individual or institution, nor are they backed by an authority. This is a challenge for the regulators. Central banks or monetary authorities must coordinate efforts in order to provide a proper and correlative regulation. The regulation must contain consumer protection rules, stakeholder protection and criminal avoidance rules.

Regulators must consider that digital currencies have zero intrinsic value, as a result, they derive value only from the belief that these currencies might be exchanged for other goods or services, or certain amount of sovereign currency. For this reason, authorities must consider that holders of digital currency may face substantially greater cost and loses associated with price and liquidity risk than holders of sovereign currency. (BIS 2OI 5: I2).

The mechanisms of regulation for digital currencies might have effects on retail payment services, monetary policies or financial stability. The increasingly use of digital currencies take place of the need of creation a new financial market infrastructure. This infrastructure might consider the existence of both currencies in the market: fiat currencies and digital currencies.

The use of Bitcoin represents a huge challenge for both regulatory authorities and customers. The nature of the digital currency schemes makes possible a better relationship between the participants in the commerce. On the other hand, the authority faces a high trouble in finding the proper regulation. 
There are some puzzles in digital currency matter. First, finding the best definition. Digital currencies have specific features that make necessary to mention in its definition. The second puzzle is the function of Internet. It is important because Internet is the vehicle for the good functioning of digital currency schemes. The network provides all the facilities to digital currency, but it also may be a place for criminal activity. The third puzzle is the relation of digital currencies and the e-commerce. The electronic commerce is an antecedent of virtual currencies. The necessity to make the payment quicker and easier makes possible the growth of virtual currencies. Finally, there is the puzzle of the regulation. A complete regulation does not exist in the digital area. It is the nature of the Internet. It is a place where there are no financial rules. Criminal activity and improper use of Internet will increase over time.

In response to the question whether people should use digital currency we will say that there is not a clear answer. It will depend on the preferences of the users. Definitely, the best example of a digital currency scheme is Bitcoin. This virtual currency is experimental. Bitcoin never will replace the fiat currency or printed money.

In the same way, the high use of digital currency will depend of the purposes of the agreement. As in all of the private transactions, the parties will agree to the terms and conditions. Then, the payment method reflects the decision of the parties. The buyers and sellers will take into account that a high level of privacy will be a high level of risk and less protection from the authority, at least for now.

\section{BIBLIOGRAPHY}

Ali, Robleh, John Barrdear, Roger Clews, and James SouthgaTE (2OI4). The Economics of Digital Currencies. Bank of England, Quartely Bulletin.

Australian Tax Office (20I4). «Tax Treatment of Crypto-Currencies in Australia - Specifically Bitcoin» Available at https://www.ato.gov. au/General/Gen/Tax-treatment-of-crypto-currencies-in-Australia--specifically-bitcoin/.

Bitcoin Fees Web Page (2015). «Bitcoin Fees I Bitcoin Transaction Fees Explained». Accessed December 3, 20I5. Available at http:// bitcoinfees.com/. 
Bitcoin Project (2015). "Bitcoin for Individuals - Bitcoin». Accessed November 9, 20I5. Available at https://bitcoin.org/en/ bitcoin-for-individuals.

-. (20I 5). «FAQ | Bitcoin.com» Accessed November 9, 2015 . Available at https://www.bitcoin.com/faq.

Davis, Joshua (20II). "The Cripto-Currency: Bitcoin and Its Mysterious Inventor» The New Yorker, October Io. Available at http:// www.newyorker.com/magazine/2011/10/10/the-crypto-currency.

Davison, Alan (2009). The Law of Electronic Commerce. Cambridge University Press.

European Central Bank (2012). «Virtual Currency Schemes». Available at https://www.ecb.europa.eu/pub/pdf/other/virtualcurrencyschemes201210en.pdf.

European Central Bank (2015). "Virtual Currency Schemes - a Further Analysis». Available at https://www.ecb.europa.eu/pub/pdf/ other/virtualcurrencyschemesen.pdf.

Financial Action Task Force (20I4). "Virtual Currencies: Key Definitions and Potential AML/CFT Risks». Available at http://www.fatfgafi.org/publications/methodsandtrends/documents/virtual-currencydefinitions-aml-cft-risk.html.

-. (2015). "Guidance for a Risk-Based Approach to Virtual Currencies» Available at http://www.fatf-gafi.org/publications/fatfgeneral/ documents/guidance-rba-virtual-currencies.html.

Fullenkamp, Connel, and Saleh Nsouli (2004). «Six Puzzles in Electronic Money and Banking» International Monetary Fund. Available at http://www.imf.org/external/pubs/ft/wp/2004/wp0419.pdf.

Gabriel, Henry (2006). "The United Nations Convention on the Use of Electronic Communications in International Contracts: An Overview and Analysis». Uniform Law Review, I I.

GrInBERG, Ruben (20I2). «Bitcoin: An Innovative Alternative Digital Currency». Hastings Science \& Technology Law Journal, I 59-208.

Hetт, William (2009). "Digital Currencies and the Financing of Terrorism». Richmond Journal of Law \& Technology, I 5 .

ICANN (2OI 5). «Resources». Available at https://www.icann.org/resources/pages/welcome-2012-02-25-en. Accessed December 23, 2015.

KATZ, Jonathan (2010). Digital Signatures. Springer.

Kien-Meng Ly, Matthew (20I4). «Coining Bitcoin's 'Legal-Bits': Exa- 
mining the Regulatory Framework for Bitcoin and Virtual Currencies». Harvard Journal of Law \& Technology, 27 (2).

KIRby, Patrick (20I4). "Virtually Possible: How to Strengthen Bitcoin Regulation Within the Current Regulatory Framework». North Carolina Law Review, 93 (I).

KoHL, Uta (2007). Jurisdiction and the Internet. Cambridge University Press.

Library of Congress of United States of America (20I4). «Regulation of Bitcoin in Selected Jurisdictions». Available at http://www. loc.gov/law/help/bitcoin-survey/.

Loubser, MM, and Derick Swart (I999). «Electronic Money in South African Law». Stellenbosch Law Review, ro.

Mıк, Eliza (20I0). «Evaluating the Impact of the UN Convention on the Use of Electronic Communications in International Contracts on Domestic Contract Law. The Singapore Example». Chinese Yearbook of International Trade Law, 28: 43-65.

Mullan, Carl (2014). Digital Currency Challenge: Shaping Online Payment System through US Financial Regulations. Palgrave Macmillan. Murphy, Edward, Maureen Murphy, and Michael Seitzinger (2OI 5 ). «Bitcoin: Questions, Answers, and Analysis of Legal Issues». Congressional Research Service.

Murray, Andrew (2010). Information Technology Law. Oxford University Press.

Naкамото, Satoshi (2009). «Bitcoin: A Peer-to-Peer Electronic Cash System». Available at https://bitcoin.org/bitcoin.pdf.

-. (2009). «Bitcoin. P2P Money». Available at https://bitcoin.org/en/.

Negurita, Octav (20I4). «Bitcoin - Between Legal and Financial Performance». Contemporary Readings in Law and Social Justice, 6.

Prins, J.E.J., P.M.A. Ribbers, H.C.A. Van Tilborg, A.F.L. Veth, and J.G.L. Van Der Wees (2002). Trust in Electronic Commerce, The Role of Trust from a Legal, an Organizational and Technical Point of View. The Hague: Kluwer Law International.

Proctor, Charles (20I2). Mann on the Legal Aspect on Money. Oxford University Press.

Reed, Chris (2004). Internet Law. Cambridge University Press. -. (20I2). Making Laws for Cyberspace. Oxford University Press.

Tucker, Peter C. (2009). «Digital Currency Doppelganger: Regulatory 
Challenge or Harbinger of the New Economy?» Cardozo Journal of International and Comparative Law, I7: 589.

Tyree, Alan (1997). Digital Cash. Butterworths.

Velde, François (20I3). «Bitcoin: A Primer». The Federal Reserve Bank of Chicago.

WAng, Faye (2010). Law of Electronic Commercial Transactions. New York: Routledge.

\section{ABOUT THE AUTHORS}

Gonzalo Arias Acuña es abogado. Licenciado en Ciencias Jurídicas por la Universidad Adolfo Ibáñez, Chile. Master en Derecho (LLM), University of Melbourne, Australia. Email: gonzalo.ariasac@uai.cl.

Andrés SÁnchez Pullas es abogado por la Universidad de las Américas. Ecuador. Master of Banking and Finance, University of Melbourne, Australia. Email: andress@student.unimelb.edu.au.

Artículo recibido el 17 de octubre y aprobado el 24 de noviembre de 2016 
